\title{
ESTUDIO DEL POTENCIAL PROBIÓTICO DE LACTOBACILOS AISLADOS DE FUENTES NATURALES
}

\author{
Karín L. Zamudio* y Amparo I. Zavaleta* \\ *Laboratorio de Biología Molecular; Departamento de Bioquímica, Facultad de Farmacia y Bioquímica, \\ Universidad Nacional Mayor de San Marcos
}

\begin{abstract}
RESUMEN
El uso de los lactobacilos como probióticos se ha incrementado debido a sus propiedades benéficas para la salud animal y humana. Con el objetivo de identificar y obtener cepas nativas de lactobacilos para ser utilizadas como probióticos, se seleccionaron 9 lactobacilos aislados de diferentes fuentes naturales. Las especies de Lactobacillus fueron identificadas por el perfil de fermentación de carbohidratos y por la Reacción en Cadena de la Polimerasa utilizando cebadores especificos diseñados a partir de los espaciadores intergénicos de los genes ribosómicos 16S-23S. Los lactobacilos seleccionados pertenecen a las especies: Lactobacilius plantarum, Lb. acidophilus, $L b$. casei y $L b$. fermentum correspondiendo en número de cepas por especie 3,3 , 2 y 1 respectivamente. El potencial probiótico de estos microorganismos se determinó por su estabilidad frente a pH ácido, su tolerancia a la bilis y a su actividad antimicrobiana contra los patógenos entéricos Iisteria monocytogenes y Escherichia coli. Se encontró que $L$ b. acidophilus 4P-1 presenta las mejores características probióticas por resistir más de 24 horas a $\mathrm{pH} 3.5 \mathrm{e}$ inhibir a los patógenos ensayados.
\end{abstract}

Palabras clave: Lactobacillus, Lb. acidophilus, probiótico, PCR, espaciadores intergénicos 165-23S, Listeria monocytogenes.

\section{ABSTRACT}

The use of the lactobacilos as probiotics has been increased due to its beneficial properties for the human and animal health. With the objective to identify and to obtain native strains of lactobacilos to be used as probiotics, 9 isolated lactobacilos from different natural sources were selected. The Lactobacillus species were identified by carbohydrate fermentation patterns and by the Polymerase Chain Reaction using specific primers designed from 16S-23S rDNA intergenic spacer regions. The selected lactobacilos belong to the following species: Lactobacillus plantarum, $L b$. acidophilus, $L b$. casei and $L b$. fermentum corresponding in number of strains by species $3,3,2$ and 1 respectively. The probiotic potential of these ricroorganisms was determined by low $\mathrm{pH}$ stability, tolerance to bile and their antimicrobial activity against the enteric pathogens Listeria monocytogenes and Escherichia coli. Lb. acidophilus 4P-1 showed the best probiotic characteristics to resist more than 24 hours at $\mathrm{pH} 3,5$ and to inhibit pathogens mentioned above.

Key words: Lactobacillus, Lb. acidophilus, probiotic, PCR, 16S- 23S intergenic spacers, Listeria monocytogenes.

\section{INTRODUCCIÓN}

El interés por el uso de los lactobacilos como probiótico en el tratamiento y prevención de enfermedades se ha incrementado de forma considerable en los últimos años; y se fundamenta en utilizar microorganismos productores de metabolitos benéficos y de agentes antimicrobianos para el control de patógenos. Los probióticos han sido utilizados cn el tratamiento de artritis reumatoide, carcinogéneșis, intolerancia a la lactosa, enferme- dad de Crohn, diarrea, candidiasis, infecciones del tracto urinario, así también como agentes inmunomoduladores y reguladores de los niveles de colesterol $(1,2,3,4)$. Numerosos estudios demuestran que la administración de lactobacilos por vía oral disminuyen significativamente la presencia de enteropatógenos en el intestino de poilos, cerdos y humanos y reestablece el balance apropiado de la flora intestinal. Los lactobacilos son considerados excelentes probióticos por ser de carácter no patogénico, inocuos, estables y viables, por resistir 
al cambio de $\mathrm{pH}$ y tener la capacidad de transformar numerosos carbohidratos. Las cepas utilizadas como probiótico deben reunir las siguientes características: I) no ser patógenas, especialmente para personas inmunodeficientes, ni estar asociadas con enfermedades, II) resistir a enzimas proteolíticas, III) ser capaces de sobrevivir en el tránsito gástrico, IV) ser estables frente a los ácidos, bilis y no conjugarse con las sales biliares, V) tener capacidad de adhesión a las células epiteliales intestinales, VI) sobrevivir en el ecosistema intestinal, VII) producir agentes antimicrobianos, VIII) presentar estabilidad durante su empleo, IX) crecer rápido en condiciones del ciego y X) tener capacidad de inmunoestimulación sin efectos antiinflamatorios $(4,5)$.

Las especies de Lactobacillus cuyos efectos probióticos han sido probados con éxito in vitro e in vivo son: Lb. rhamnosus, Lb. acidophilus, Lb. casei, $L b$. reuteri, Lb. fermentum y $L b$. plantarum $(2,5)$. En el presente estudio, se utilizaron cepas de lactobacilos aislados de diferentes fuentes y que fueron seleccionadas por sus propiedades probióticas ensayadas en la inhibición de patógenos entéricos. Los aislados fueron previamente identificados por pruebas bioquímicas de fermentación de carbohidratos y por la Reacción en Cadena de la Polimerasa (PCR) utilizando cebadores específicos diseñados a partir de los espaciadores intergénicos entre los genes ribosómicos 16S-23S $(7,8,9)$.

\section{MATERIAL Y MÉTODOS}

\section{bioquímica \\ Condiciones de cultivo e identificación}

Lactobacilos de diferentes orígenes (10), asi como las cepas de colección: $L b$ plantarum CECT 748, $L b$ casei CECT 475, $L b$ acidophilus CECT 362 y Lb. fermentum CECT 4007 , se sembraron en medio sólido específico Man Rogosa Sharpe (MRS) a $30^{\circ} \mathrm{C}$ por $48 \mathrm{~h}$ en microanerobiosis. Para la prueba de fermentación de carbohidratos, se inoculó $100 \mu \mathrm{l} \mathrm{del}$ cultivo fresco en caldo MRS modificado (11) adicionando rojo de clorofenol al $0.004 \%$, y el carbohidrato (fructosa, manitol, xilosa, maltosa, sorbitol, sucrosa, manosa) al $0.05 \%$, se incubó a $30^{\circ} \mathrm{C}$ por 48 horas y se procedió a la lectura de los resultados.

\section{Identificación molecular}

Se utilizó la PCR con cebadores específicos diseñados a partir de los espaciadores intergénicos de los genes ribosómicos 16S-23S y del 16S, cuyas características se presentan en la tabla 1. La mezcla de reacción consistió en un volumen final de $50 \mu \mathrm{l}$ que contenía aproximadamente $50 \mathrm{ng}$ del ADN genómico, dNTP $200 \mathrm{uM}$, de cada cebador $25 \mathrm{pmol}$, $\mathrm{MgCl}_{2} 1.5 \mathrm{mM}$ y Taq DNA polimerasa 1 U. Las condiciones de reacción fueron un ciclo de desnaturalización a $95^{\circ} \mathrm{C}$ por 3 minutos, 30 ciclos con las siguientes etapas: Desnaturalización $94{ }^{\circ} \mathrm{C}$ por 3 segundos, alineamiento según cebador (tabla 1) por 30 segundos, polimerización a $72{ }^{\circ} \mathrm{C}$ por 45 segundos y un ciclo final de polimerización a $72{ }^{\circ} \mathrm{C}$ por 2 minutos. El producto de PCR se separó por electroforesis en geles de agarosa al $1.2 \%$ con buffer TBE $1 \mathrm{X}$ a $80 \mathrm{~V}$.

\section{Ensayo de la actividad antimicrobiana}

Se utilizó un cultivo en caldo MRS de 48 horas y se concentraron las células por centrifugación a $3500 \mathrm{rpm}$ por 30 minutos. $100 \mu \mathrm{l}$ del sobrenadante, que contenía las sustancias liberadas, se colocó en los pocillos que se formaron por torres de acero inoxidable en el agar Mueller Hinton; previamente se inoculó a placas distintas aproximadamente $3 x$ $10^{8}$ Unidades Formadoras de Colonia (UFC) de Listeria monocitogenes ATCC 19118 o E. coli ATCC 43887. Se incubó a $30^{\circ} \mathrm{C}$ por 24 horas y se midió el diámetro de cada halo de inhibición. Determinación de la capacidad de crecimiento a
diferente pH

Esta prueba se realizó en matraces de $250 \mathrm{~mL}$ de capacidad que contenían $30 \mathrm{ml}$ de caldo MRS; el $\mathrm{pH}$ inicial de cada caldo se ajustó a 6.2, 4.0, 3.5, 3.0 y2.5, se esterilizó a $121^{\circ} \mathrm{C}$ por 15 minutos. Se inoculó $10^{7} \mathrm{UFC} / \mathrm{mL}$ de cada cepa con 24 horas de crecimiento. Los cultivos se incubaron en microanareobiosis a $37^{\circ} \mathrm{C}$ durante 24 horas y se tomaron muestras a las 0,12 y 24 horas para el recuento de células viables por siembra en agar MRS.

Determinación de la capacidad de crecimiento a $0.15 \%$ de bilis

Al medio MRS se le ajustó el pH inicial a 5.5 y se inoculó con $10^{7} \mathrm{UFC} / \mathrm{mL}$ e incubó a $37^{\circ} \mathrm{C}$ en microanareobiosis; en seguida se tomaron muestras a las 0, 12 y 24 horas para el recuento de células viables por siembra en agar MRS. 


\section{RESULTADOS}

A los 9 lactobacilos aislados de diferentes fuentes naturales, primero se les identificó a qué especie pertenecen, mediante las pruebas de fermentación de carbohidratos. En la lectura e interpretación de los perfiles bioquímicos correspondientes a las especies de Lactobacillus, se utilizaron las tablas descritas en el manual Bergey, así como los mostrados por las cepas de colección: Lb. plantarum CECT 1234, Lb. casei CECT 4678, Lb. acidophilus CECT 3895, Lb. fermentun CECT 3678.

La capacidad de degradación de los azúcares por los diferentes aislados se presenta en la tabla 1. En esta se observa que cada lactobacilo muestra un perfil metabólico característico que no permite una identificación precisa al compararlo con los descritos en el Manual Bergey; ejemplo de estos casos se presenta con los aislados $\mathrm{Y}-7, \mathrm{Q} 17-2, \mathrm{Q} 2-3$ y $5 \mathrm{P}-2$.

La prueba de PCR utilizando cebadores específicos a partir de las zonas conservadas de las regiones intergénicas de los genes ribósomicos 16523S, permitió identificar los 9 lactobacilos obtenidos de diferentes muestras naturales. En la tabla 2 se presenta el número de cepas por especie identifi- cada, las características de los cebadores utilizados y los tamaños de los productos amplificados. Los cebadores dan origen a productos de PCR de diferentes tamaños, siendo estos de 520,500, 450 y 420 pb para las especies $L b$ : acidophilus, $L b$. casei, $L b$. plantarum y $L b$. fermentum respectivamente.

La actividad antibacteriana se determinó midiendo el halo de inhibición de cada cepa frente a los enteropatógenos Listeria monocytogenes y Escherichia coli; : siendo uno Gram positivo, y el otro, Gram negativo. Estos microorganismos se eligieron por estar disponibles en el laboratorio, ser diferentes y tener un alto riesgo para la salud. Los halos de inhibición variaron entre 2 a $>8 \mathrm{~mm}$ siendo las cepas Q17-2, 4P-1 y Y-7 las que mostraron un mayor halo de inhibición (tabla 3). Asimismo, se evaluó la resistencia a pH ácido tolerancia a bilis por considerarse estos parámetros fundamentales para ser seleccionado como probiólico. La cepa 4p1, aislada del tracto gastrointestinal de pollo mostró las mejores características probióticas por resistir a pH 3.5 presentando un btien crecimiento, siendo este de $10^{9} \mathrm{UFC} / \mathrm{mL}$ adecuadas para este tipo de preparados (fig.1) y mantenerse viable al $0.15 \%$ de bilis, así como presentar un mayor halo de inhibición frente a los patógenos ensayados (tabla 3).

Tabla 1. Fermentación de carbohidratos de los lactobacilos aislados de diferentes fuentes naturales

\begin{tabular}{|c|c|c|c|c|c|c|c|c|c|c|c|c|c|}
\hline Fruebas & $\begin{array}{l}0 \\
0 \\
\frac{12}{2} \\
\frac{5}{8} \\
\frac{\varepsilon}{0}\end{array}$ & 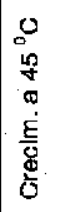 & 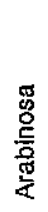 & 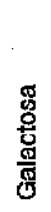 & $\begin{array}{l}\text { gू } \\
\text { g్ } \\
\text { g }\end{array}$ & 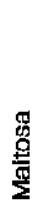 & $\frac{\bar{g}}{\stackrel{5}{E}}$ & $\begin{array}{l}\text { 总 } \\
\frac{0}{0} \\
\text { 음 } \\
\text { 要 }\end{array}$ & 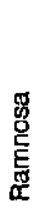 & $\begin{array}{l}\overline{0} \\
\text { 음 } \\
\text { o }\end{array}$ & 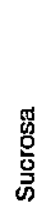 & 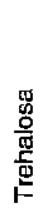 & $\begin{array}{l}\text { 吕 } \\
\text { o } \\
\stackrel{3}{x}\end{array}$ \\
\hline Q2-3 & + & + & - & + & - & + & + & + & - & 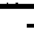 & + & $t$ & - \\
\hline Q7-3 & - & + & + & + & - & + & ? & + & + & - & + & + & $t$ \\
\hline LAB-6 & + & - & + & - & - & + & $t$ & + & - & + & + & - & - \\
\hline Q17-2 & + & - & + & + & - & d & + & + & - & + & + & - & - \\
\hline $2 \mathrm{P}-1$ & + & $=$ & - & + & - & + & + & + & - & + & + & - & - \\
\hline $4 \mathrm{P}-1$ & - & + & $\cdot$ & + & + & + & - & - & - & - & + & + & - \\
\hline $5 P-2$ & $\cdots$ & + & $\cdot$ & + & + & + & $\cdot$ & $t$ & - & . & + & 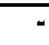 & - \\
\hline$Y-5$ & $=$ & + & 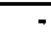 & + & - & + & d & + & 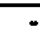 & - & + & $=$ & $\cdot$ \\
\hline$Y-7$ & - & + & $\cdot$ & - & + & + & $\cdot$ & + & - & + & + & - & - \\
\hline
\end{tabular}

$(-)$, no fermenta; $(+)$, fermenta; (d), no determinado 
Tabla 2. Oligonucleótidos específicos para identificar las especies de Lactobacillus por PCR

\begin{tabular}{|c|c|c|c|c|}
\hline 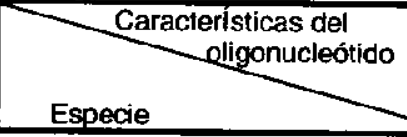 & Nombre & Secuencia $\left(5^{\prime} \rightarrow 3^{\prime}\right)^{*}$ & $\begin{array}{l}\mathrm{Tm} \\
\left({ }^{\circ} \mathrm{C}\right)\end{array}$ & $\begin{array}{l}\text { Producto de PCR } \\
\text { (pb) }\end{array}$ \\
\hline Lactobacillus casel & $\begin{array}{l}\text { Pri } \\
\text { Casll }\end{array}$ & $\begin{array}{l}\text { CAGACTGAAAGTCTGACGG } \\
\text { GCGATGCGAATTCTTITC. }\end{array}$ & 55 & 500 \\
\hline Lactobacifus plantarum & $\begin{array}{l}\text { Lfpr } \\
\text { Planll }\end{array}$ & $\begin{array}{l}\text { GCCGCCTAAGGTGGGACAGAT } \\
\text { TTACCTAACGGTAAATGCGA }\end{array}$ & 55 & 450 \\
\hline Lactobacillus acidophitus & $\begin{array}{l}\text { Aci } 16 \mathrm{SI} \\
16 \mathrm{SH}\end{array}$ & $\begin{array}{l}\text { AGCTGAACCAACAGATTCAC } \\
\text { ACTACCAGGGTATCTAATCC }\end{array}$ & 62 & 520 \\
\hline Lactobacillus fermentum & $\begin{array}{l}\text { Lprf } \\
\text { Fermll }\end{array}$ & $\begin{array}{l}\text { GCCGCCTAAGGTGGGACAGAT } \\
\text { CTGATCGTAGATCAGTCAAG }\end{array}$ & 55 & 420 \\
\hline
\end{tabular}

* información obtenida de Walter y col. (2000)

Tabla 3. Especies de Lactobacillus según origen de procedencia y actividad antibacteriana

\begin{tabular}{|l|l|l|c|c|}
\hline \multirow{2}{*}{ Especie } & \multirow{2}{*}{ Cepa } & Origen de procedencia & \multicolumn{2}{c|}{ Actividad antibacteriana } \\
\cline { 3 - 5 } & & & \multicolumn{2}{c|}{$\begin{array}{c}\text { Listeria } \\
\text { monocytogenes }\end{array}$} \\
\hline Lb. plantarum & & & + & + \\
\hline Lb. casei & Lab-6 & Bebida fermentada & + & + \\
\hline Lb. casei & Q2-3 & Queso artesanal & ++ & + \\
\hline Lb. plantanum & Q7-3 & Queso artesanal & ++ & + \\
\hline Lb. plantarum & Q17-2 & Queso artesanal & + & ++ \\
\hline Lb. acidophilus & $2 \mathrm{p}-2$ & Tracto Gl de pollo & ++ & + \\
\hline Lb. acidphilus & $4 \mathrm{p}-1$ & Tracto Gl de pollo & + & + \\
\hline Lb. acidofhilus & $5 \mathrm{p}-2$ & Tracto Gl de pollo & + & + \\
\hline Lb. fermentun & $\mathrm{y}-5$ & Yogurt natural & ++ & + \\
\hline
\end{tabular}

Halo de inhibición: $(+)$, entre 2 y $5 \mathrm{~mm} ;(++),>5 \mathrm{~mm} ;(-)<1 \mathrm{~mm}$.

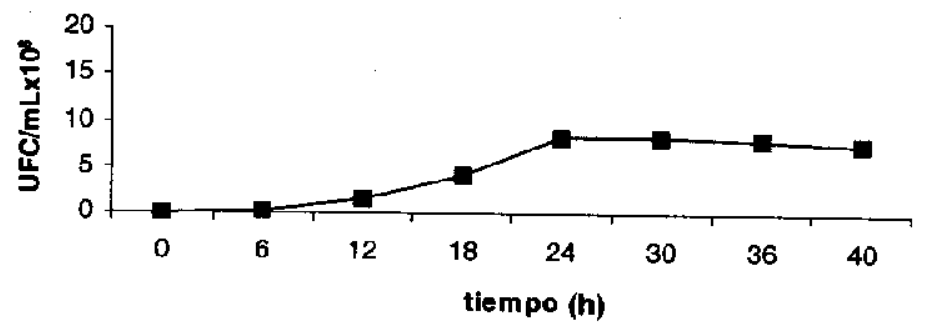

Figura 1. Curva de crecimiento del aislado 4P1(-) y Lb.acidophilus CECT 362 (ت)a pH 3.5. 


\section{DISCUSIÓN}

Las bacterias del género Lactobacillus denominadas como seguros o GRAS (Generally Recognized as Safe) son microorganismos Gram positivos, catalasa negativo, no esporulados, inmóviles y fermentadores; estas características permitieron seleccionar 9 lactobacilos de diferentes orígenes descritos en trabajos previos $(4,10,12)$.

Los lactobacilos seleccionados comparten muchas características metabólicas, que no permiten identificar con certeza a la especie que pertenecen. Así, los aislados Q2-3 y Q7-3 tienen diferentes perfiles de fermentación para arabinosa, manitol, ramnosa y xilosa (tabla 1), que si comparamos su lectura con los del manual Bergey indicaría que son especies distintas si solo se consideran estas pruebas metabólicas. Sin embargo, cuando se utilizaron las pruebas biomoleculares, los dos aislados pertenecen a una misma especie; estas diferencias indican que las características fenotípicas generalmente no se relacionar con las genotípicas.

La zona intergénica entre los genes ribosómicos 165 y $23 S$ es altamente conservada para cada especie del género Lactobacillus, a su vez muy polimórfica en secuencia y tamaño entre las especies del mismo género. Estas características han pcrmitido diseñar cebadores universales para identificar y caracterizar diferentes especies y cepas bacterianas $(7,8,9)$. El uso de cebadores específicos para los espaciadores intergénicos 16S-23S y genes ribosómicos 16S (tabla 2) en la técnica de la PCR permitieron determinar la especie de los lactobacilos aislados de diferentes orígenes.

La mayor dificultad que presentan los lactobacillus utilizados hoy en día para la elaboración de un gran número de productos alimenticios convencionales radica en su baja capacidad de supervivencia durante su paso por el estómago y el duodeno, ya que para lograr un efecto positivo de estos microorganismos sobre la flora intestinal es esencial que sean capaces de adaptarse en el intestino y competir con la flora nativa existente (7). La mayoría de lactobacilos estudiados presentan gran estabilidad a los ácidos y bilis, y producen sustancias antimicrobianas que inhiben la flora patógena por efecto competitivo $(1,3,6)$. La supervivencia a altas concentraciones de ácido es fundamental para el buen funcionamiento del microorganismo como probiótico, ya que el mismo puede estar sometido en su paso a través del estómago y el intestino a
pHs que pueden alcanzarvalores de 3.0, o menores (6). En este sentido $L b$. acidophilus $4 \mathrm{P} 1$ presentó las mejores características de estabilidad frente a ácidos y bilis; este microorganismo podría ser utilizado como productor de antimicrobianos en la industria láctica para disminuir el número de casos de intoxicación alimentaria por L. monocytogenes, un patógeno emergente y de alto riesgo.

Las características de tolerancia a $\mathrm{pH}$, bilis y actividad antimicrobiana presentadas por las cepas estudiadas requieren ser complementadas con la prueba de adherencia en la línea celular Caco-2 antes de explorar sus bondades probióticas en la industria alimentaria.

\section{AGRADECIMIENTOS}

Agradecemos a la Colección Española de Cultivos Tipo por proporcionarnos las cepas utilizadas en el presente estudio.

\section{REFERENCIAS BIBLIOGRÁFICAS}

1. Charteris WP., Kelly PM, Morelli L. and Collins J.K. 1997. Selective detection numeration and identification of potencially probiotic Lactobacillus and Bifidobaclerium species in mixed bacterial populations. Int. J. Food Microbiol.35:1-27

2. De Ross N.M. and Katan B.M. 2000. Effects of bacteria on diarrhea, lipid metabolism, and carcinogenesis: a review of papers published between 1988 and 1998. Am .J.Cln.Nutr. 71:405411.

3. Pal Kaur I., Chopra K. and Sain A. 2002. Probiotics: potencial pharmaceutical applications. Eur.J.Pharm.Sci. 15:1-9.

4. Reid G. 1999. The scientific basis for probiotic strains of Lactobacillus. Appl. Environ. Microbiol. 65:3763-3766.

5. Heller K. J. 2001. Probiotic bacteria in fermented foods: product characteristic and starler organisms. Am. J. Clin. Nutr. 73:374-379.

6. Kirjavainen P.V., Ouwehand A.C., Isolauri E. and Salminen S.J. 1998. The ability of probiotic bacteria to bind to human intestinal mucus. FEMS Microbiol. Lett.167:185-189

7. Walter J., Tannock W., Tilsala-Tamisjarvi A., Rodtong S., Loacih S.M., Munro K. and Alotossva T. 2000. Detection and identification 
of gastrointestinal Lactobacillus species by denaturing gradient gel electrophoresis and species-specific PCR primers. Appl. Environ. Microbiol. 66:297-303.

8. Yeung P.S., Sanders M.E., Kitts C. L., Cano R. and Tong P.S. 2002. Species-specific identification of commercial probiotic strains. J.Dairy Sci. 85:1039-1051.

9. Zhong W., Millsap K., Bialkowska-Hobrzansk H., and Reid G. 1998. Differentiation of Lactobacillus species by molecular tiping. Appl. Environ. Microbiol. 64:2418-2423

10. Zamudio K.L., Negron L. and Zavaleta A.I. 2003. Identificación molecular de especies del género Lactobacillus productores de exopolisacáridos de interés biotecnológico. Libro de Resúmenes del V Congreso Nacional de Ciencias Farmacéuticas y Bioquímicas. Trujillo.
11. Kimmel S.A., Roberts R.F. and Ziegler G.R. 1998. Optimization of exopolysaccharide production by Lactobacillus delbrueckii subsp bulgaricus RR grown in a semidefined medium. Appl. Environ. Microbiol. 64: 659-664.

12. Snerth P.H.A., Mair N.S., Sharpe M.E. and Holt J.E. 1986. Bergey's manual of systematic bacteriology. Vol. 2. Williams and Wilking, Baltimore.

13. Olsen A., Halmand M., Jacobsen M. 1995. The antimicrobial activity of lactic acid bacteria from fermented maize (kenkey) and their interaccions during fermentation. J.Appl. Bacteriol.74:506-512

14. Klanenhmmer T.R. and Kullen M.J. 1999. Selection and design of probiotic. Int. J. Food Microbiol. 50:45-47 